\title{
Studio_L28: From a Socially Engaged Sound Art Practice to an Open Training Ground for Sonic Design Experimentation
}

\author{
Caroline Claus ${ }^{1}$ and Burak Pak $^{2}$ \\ ${ }^{1}$ Ph.D. Student, Altering Practices for Urban Inclusion Research Group, Department of Architecture, \\ KU Leuven, Brussels \\ ${ }^{2}$ Professor, Altering Practices for Urban Inclusion Research Group, Faculty and Department of \\ Architecture, KU Leuven, Brussels
}

\begin{abstract}
This paper reflects the preliminary findings of a $\mathrm{PhD}$ research on the spatial politics and potentials of noise and vibration, and the affective or attractive and repulsive power of sonic force. We focus on the public space of a railway area in transformation in Brussels, where sonic conflicts are prevalent. To explore the affordances of a sonic urbanism as critical spatial practice and thus to break free from prevailing modes of urbanism which focus on sonic risk and vibrational nuisance - we constitute a working practice exploiting and nurturing the productive encounters between disciplines such as sound art, urbanism and urban architecture. By setting up an experimental design studio at the KU Leuven Faculty of Architecture, embedded in local auditory culture and in connection to ongoing planning processes, we aimed to facilitate an open learning ground for sonic design experimentation in the development of innovative sonic spatial tools and approaches. The studio was oriented to students of the International Master in Architecture summoned to research the multiple (sonic) vibrations of the L28 railway area, to exploit and contrast these vibrational forces, transforming them to into actions and opportunities. From a critical sonic understanding of urban space, students played and explored a contradictory role compared to the widespread noise control practices, reformulated environments, perimeters and relations of urban phenomena and searched for interactivity with vibrational dynamics that already exist in the territory.
\end{abstract}

\section{Introduction}

Under the guidance of Prof. Dr. Burak Pak and Caroline Claus, eleven students of the KU Leuven International Master in Architecture enrolled in a fourteen-week urban sound design research project. In this paper we introduce the experimental design studio operating as a reflexive inquiry, an engagement with students in architecture and as to its own purpose. In what follows we will explore the following questions:

- What are the affordances of a sonic urbanism as critical spatial practice situated in a design studio?

- How can an urban-architecture design studio be an open testing ground for learning and exploring novel forms of sonic urbanism?

- How can practitioners and students learn from different disciplines, and reformulate it into a new way of operation?

- What are the alternative strategies for engagement, critical and spatial design? 


\section{Studio_L28 as critical learning experiment}

The Masterstudio_L28 was a fourteen-week design studio we organized in autumn 2018 at the KU Leuven Faculty of Architecture, Brussels. Together with sound artists and curators, and students of the KU Leuven International Master's in Architecture, the potential of urban sound design for public urban space has been explored from different critical spatial perspectives. Rather than an educational program the KU Leuven Masterstudio_L28 was conceived as a platform for learning. In this context learning is understood as means of developing ideas in collaboration with students and sound artists, outreach workers and architects. We have aimed to facilitate the production of critical ideas and motivated the students to create exploratory projects as a means for presenting and testing these ideas.

\subsection{Research Context}

KU Leuven Masterstudio_L28 is part of the ongoing PhD project: The Vibrational Nexus with Prof. Dr. Burak Pak as supervisor and Peter Cusack as co-supervisor. The research has its roots in an interdisciplinary project Caroline Claus realized in collaboration with the Brussels workspace for sound art, Q-O2 and public school for architecture Brussels [1] and her long-term involvement in the planning processes for public railway space along the railway line L28 [2]. The PhD research project explores the position and role of (sonic) vibrations in public space development along Brussels Western ring railway line L28.

Open space along the Western ring railway L28 has long time been marginalized in Brussels planning processes [3]. The development of public space on former railway land is relatively new here. Because of its natural, historical and ecological richness and the recent plans for development and transition [4, 5], the railway area of the L28 line can be considered as an excellent object for research into sound and urban public space development. In the official planning processes (sonic) vibrations are dominantly discussed as a nuisance to suppress. Our interest, by contrast, is focused on the quality of sound and vibration in relation to urban transformation, mobilization and transition.

For his ecological theory on sonic warfare, philosopher, musician and label owner, Steve Goodman [6] points to the importance of understanding the agency of vibrational matter and the shortcoming of anthropocentric conceptions. Accounts of the sonic in terms of conscious hearing or listening are troubled by Goodman in favour of an unconscious, affective account of sound as material impact, hereby opening up to the inaudible frequencies. Goodman describes the vibrational nexus as each actual occasion of experience that populates the discontinuum, drawing in an array of elements into its collective shiver. The conception of a differential ecology of vibrational effects leads him towards a non- anthropocentric ontology of ubiquitous media, a topology in which every resonant surface is potentially a host for contagious concepts, percepts, and affects.

Understanding the open space of an urban railway area in transition as a discontinuum of sonic and vibrational possibilities determined by more actants than human sounds, encourages a revision of dominant sonic approaches, method and tools used in the urban design process as we know it. A decentering of the human sense and perspective seems to have implications for the urban design it constrains. Building on Goodman's theoretical work, we adopt Augoyard and Henri Torgue's definition of a sonic ecology [7] in a proposal for a sonic urbanism as critical spatial practice.

From a questioning of the ontological turn in sound studies the Ph.D. research project elaborates upon the following positions and propositions: 1) human and non-human actants co-constitute a discontinuum of sonic and vibrational possibilities, 2) we need an a- 
disciplinary rethinking of sonic forms and methods for urban sound design and, 3) (sonic) vibrations as design material opens up to a re-negotiation of urban transition.

\subsection{Critical learning}

The design studio is the heart of architecture and urban design education [8]. It is a place for "reflection-in-action" through which students learn experientially by designing their own projects. Yet, this reflectivity is mostly limited to the individual interactions in a traditional studio setting: design studio in this limited form is predominantly mono-disciplinary, predominantly teacher and student-centered [9]. In this context, rethinking the design studio as a medium for learning critical spatial practice required the use of particular strategies and methods.

Critical spatial design aims to go beyond architecture as a physical construction and explore the construction of alternate realities, criticizing existing protocols, and generating new protocols for this venture [10]. In the studio we introduced sonic spatial perspectives for understanding and intervening in public space as a means to enable a critical version of the 'reflective practicum in designing' [11]. This involved developing the students' capacity of reflecting-in-action and reflecting-on-action as a crossbencher and going off of autopilot, in other words, instead of blindly following and repeating what the students learned in the past, questioning the existing protocols within the field of architecture with the will to develop new critical practices. This required students and studio coordinators to get out of the comfortable boundaries of traditional expertise in architecture, towards the unknown, the intentional and skilful mastering of incompetence in the ocean of practices [12].

An important challenge in this task was to extend the understanding of architecture towards the non-physical. Architectural design as a discipline has long been suffering from the long-time isolation of the spatial from the social and the sonic which assumes space an independent construct. However, it is impossible to understand the space without taking into consideration the social conditions as well as its sonic qualities. Rethinking architecture as a sonic and social composite opened up possibilities to develop a polyphonic approach to the re-articulation of the design practice [13] and enabled us to go beyond the physical and explore new realities, critically questioning the existing protocols and rewriting them when necessary.

For Schön each design move of the student is a local experiment which contributed to the global experiment of reframing [14, 15]. Motivating making experimental actions-design moves generated effects in the situation. These effects formed a circular feedback loop, a conversation between the student, studio coordinator and the situation to articulate, modify or reframe the existing design approach, method, tools and protocols [16]. While the situation was changing, the design ideas and protocols shifted, and at the end of the process the student in conversation with the studio coordinators invented a new way of thinking about a particular situation. Examples of these were sonic sections and sonic-spatial cartographies discussed in the following section.

\subsection{Program, methods and tools}

The KU Leuven Masterstudio_L28 happened in fourteen weeks and was built around six strategies for facilitating sonic urbanism as a critical spatial practice:

1. A series of class sessions

2. Soundwalks

3. Individual field sessions

4. Exercises in sonic representation 
5. Interdisciplinary conversation

6. Synthetic assignment

In a series of eighteen class sessions, we have introduced and discussed different sonic perspectives for a re-reading of existing planning and design tools. This has facilitated an iterative design process. During the process we have urged students to equip themselves with the needed skills to redeploy techniques and invent novel cognitive and material tools.

Building on Guy Debord's [17] theoretical work on drifting and Hildegard Westerkamp's [18] definition, we have curated a soundwalk for an explorative observation of the open railway space in relation to the subjective experience of place, and the idea of moving narratives while walking and listening. As a warm-up before the walk, we also did an exercise in voice spatialization. The soundwalk was introduced as a tool for the training of a heightened listening awareness of urban context and place, to explore the idea of a nonhuman experience of (sonic) vibrations, and to learn how to employ that into design research.

The program has encouraged individual fieldwork on site. Field recording was explored as a step towards critical cartography. Students were asked to search individually for the sonic qualities of an open railway space they were interested in. We have introduced them to different techniques for listening, recording and representing to grasp and map urban sonic quality. Students were asked to develop a graphical notation system which integrates the sonic, spatial and social characteristics of the railway space of their choice.

For a training in the representation of urban sound we have worked with exercises on how to make a sonic image of an architectural project. We have discussed the idea of a sonic section as a tool for the systematic study of the sonic and spatial qualities of an urban space and the option to work with the sonification of design ideas. Students were introduced to various composition techniques coming from sound art, music and/or choreography and a series of computer-aided simulation and sonification tools as possible resources for an advanced elaboration of their design project.

Through network practice we have facilitated an interdisciplinary conversation on methods and tools applied in a context of sound art, urbanism, and urban activism. Students were asked to exploit a contradictory role compared to the widespread noise control practices, reformulated environments, perimeters and relations of urban facts and to search for interactivity with (sonic) vibrational dynamics on the territory.

For the final assignment we asked students to develop an urban architectural project consisting of experimental sonic spatial forms with reference to sonic theory, histories of sound art and experimental music. Each student was asked to represent an urban sound strategy by use of graphical images, written text, and a sonic image or sound file. One of the things we as atelier coordinators have stressed along the process, was that we were less interested in formalistic urban architecture and more in the possibilities of intervening in the agency, the experience of formal-mechanic dimensions of urban sonic vibrations as a source for a re-negotiating of urban transformation.

\section{Studio_L28 as facilitator for sonic spatial design}

Having outlined the context of the design exercise, an a-disciplinary research project in which urban sound design forms a methodically bridging between the concerns of sound art, urbanism and urban architecture, in what follows we examine student's work as experimentations in urban sonic form and architectural design. In our dispositive of critical spatial practice-based learning: we endeavour to identify and assess critical positions, the search for new methods and tools for the analysis and definition of urban sonic forms taking into account dispositives coming from sound arts, architecture and the urban context, that is the transforming railway area of the line L28. In the next section, we will reflect on students' 
projects in relation to the $\mathrm{PhD}$ research project positions and propositions. We will discuss sonic approaches, methods and tools employed, whether or not a transdisciplinary shift appeared, and to what extent role expectations and requirements led to friction. In the following part we therefore discuss the final design proposals, the introduction to new sonic spatial forms for urban re-negotiation.

\subsection{Positions}

The interdisciplinary notion of sonic effect as developed by Augoyard and Henri Torgue's [19] has been adopted in half of the projects. It was used as a building block for new tools such as a new typology of design interventions. Some students have directly applied one or more of the defined effects in their project proposal. Although originally conceived as a human centered approach, it was also used for a connection with non-human agency. One student, Alex Auris Gonzales has used it as a starting point for his experimental approach to sonic vibrations of an underground railway track. Sarah Thorisaen researched by design how non-human agency can play a role in the improvement of urban quality. She has explored possible sonic effects of different types of plants. The focus on sonic experience of urban space has prompted most of the students to experiment with techniques such as the interview or survey, narrative explorations, field recording of sounds in relation to the built environment, contrasting qualitative research with the decibel approach used by authorities and planners. From this position, different other disciplines were approached, without really leaving the discipline of architecture.

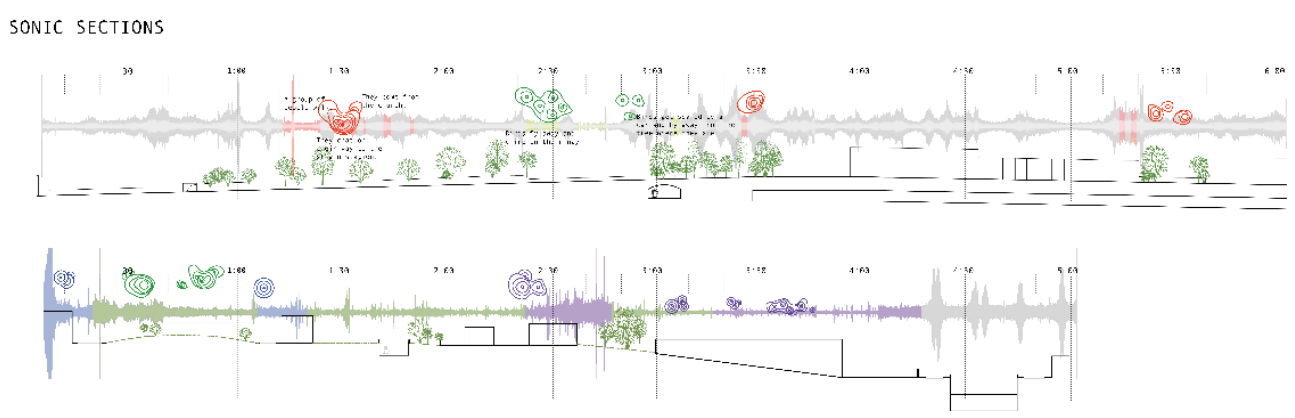

Fig. 1. Sonic sections by Alex Auris Gonzale 

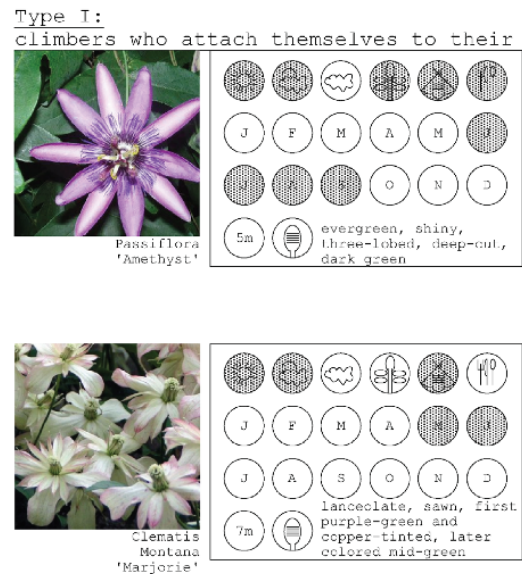
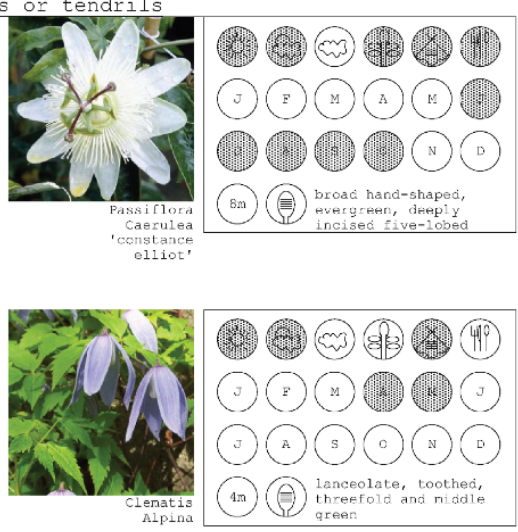

Fig. 2. Fragment of the study of sonic effects of different plants by Sarah Thorisaen

Two students have searched for a positive approach to urban noise in relation to the urban context of the railway space. Both positioned themselves, as crossbencher, in opposite to the dominant approach followed by Brussels authorities and urban planners and architects involved in the on-going development of a socio- recreational green infrastructure space along the line L28. From these radical positions the students have developed a series of punctual solutions for railways space bordering the railway line. Their design approach we consider as transdisciplinary in nature. Vilius Balčiūnas, has integrated techniques such as soundwalk, field recording, literature studying a critical cartography. Melissa Ince went for a study of the experience of noise in the existing socio- recreational green infrastructure space by focussing on different types of users. Both students have integrated methods and techniques coming from different disciplines for combining spatial qualities, urban culture and sonic aesthetics in their sonic design approach. Two other students, Daniel Dent Murgui and Eman Afanen have used a transdisciplinary approach as the starting point for the design of a performative installation they. Finally, we found these crossbenchers adopting an artistic position.
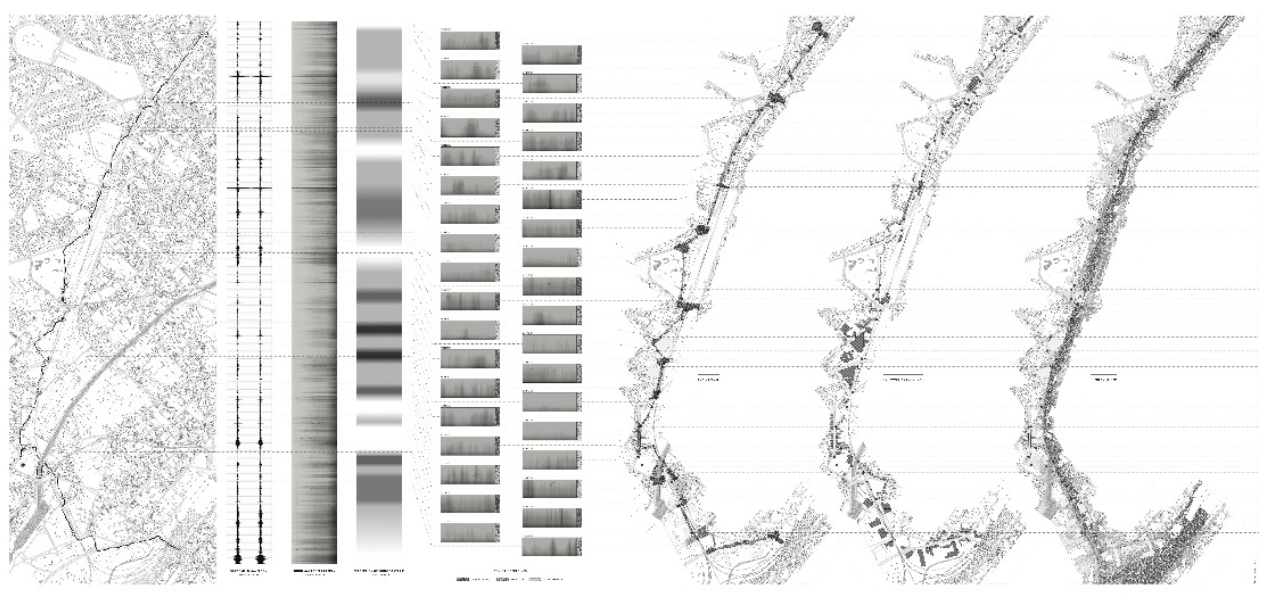

Fig. 3. Fragment of the research into sound out of place by Vilius Balčiūnas 
Three students have operated from within the discipline of architecture without much confrontation with other disciplines. Using the theoretical work on aural architecture as a starting point, Leonie Van Bellingen has developed a personal approach that allowed her to go beyond the physical, hereby exploring new connections for urban inclusion. Two students opted for a system-based design approach. Where Mateusz Modzelewski, inspired by the open structure of Oskar Hansen, ended up with a human centered approach, Asa Pelin opted for an approach based on parametric and algorithmic design.

\subsection{Sonic Spatial Forms}

Dealing with sonic spatial qualities not present in other analyses of the area, we have touched upon the limits of dominant planning and design approaches. What appeared in the design process are spatial qualities, urban atmospheres contributing to a particular identity for the urban space in transformation. The final projects highlight different possible sonic approaches to a variation of transitioning aspects. Each project illuminates or introduces elements for listening or other ways of sonic vibrational experience. Different modes of sonic experience are articulated through design: from a focus on hearing a sound source, to aural attention to formal or structural details and their arrangement in space and time. Students relate differently to transitioning space and facilitate new ways of negotiation, inclusion, autonomy - who gets it in/out? Not all students have designed for a re-negotiation of urban transition by virtue of being made aware of the contingent aspects of a sonic experience, and capable of re-engineering the control-panel. Some design projects facilitated rule governed selection, the installation of a protocol, an exercise in autonomy: a subjective experience or relation to urban transition as negotiable.

In several projects the adoption of a phenomenological approach led to a punctual urban sound design proposal. Two students proposed a series of sonic spatial design interventions based on different sonic effects listed in the catalogue of Augoyard and Torgue [20]. The design projects introduced a collection of new aesthetic qualities to strengthen the social and cultural appropriation of a future railway park/place. Punctual interventions are added to stimulate the participation of an audience. Another project consists of a spatial structure that offers space for non-human agency in support of a new sonic identity for the Weststation housing complex area.

Following a positive noise approach two students have designed for a controlled aesthetic acceptance of urban noise. The experience of a series of types of urban noise is included in the design for a network of public railway park/spaces. The idea of a sonic sequence is also present in a landscape project that starts from the vibrational experience of an underground railway. These design solutions are transdisciplinary in nature and are oriented towards a future development of new sonic spatial forms for socio - recreational green infrastructure space in Brussels Capital Region. The rather experimental forms open up to a multiple appropriation of future public railway space.

Performative installations designed by Daniel Dent Murgui and Eman Afaneh are conceived as an infrastructure to augment peoples experience of railway space in transformation. The installations reinforce the interplay between human and non-human relations on one side and between sound and vision on the other. The temporary infrastructure project by Daniel Dent Murgui collects various passive audio techniques and converts them into active tools for a participatory intervening in railway rhythms. Both installations demonstrate how a critical sonic approach can play a role in a (re) negotiation of urban transition. 


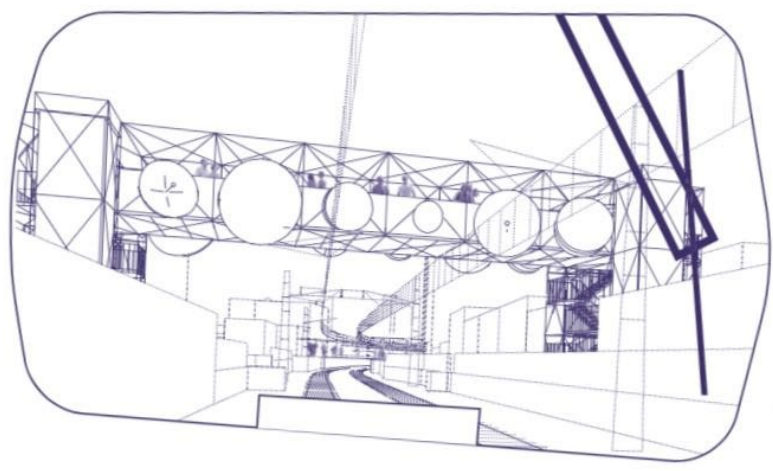

Fig. 4. Project for empowerment by Daniel Dent Murgui
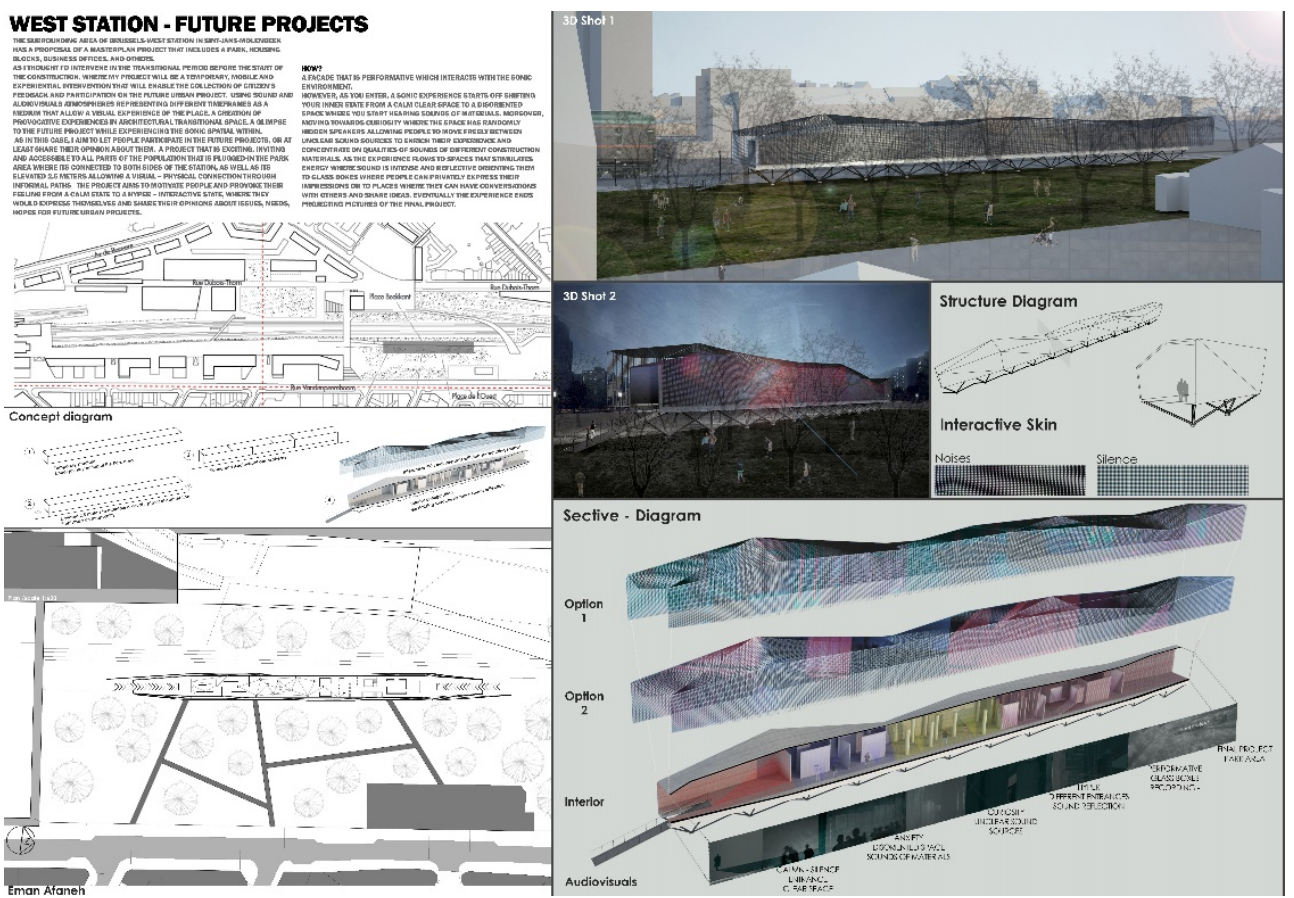

Fig. 5. Transitional Architecture by Eman Afaneh

Three projects evolved from a more practical perspective and concrete architectural approaches. Via an interweaving of acoustic elements in the design for tactile interventions the students have explored and illustrated the negotiability of sound in the architectural scale of urban space. Inspired by the idea of an acoustic arena as defined by Blesser en Salter [21], Leonie Van Bellingen has designed a series of three arena's that act as an interactive and socially, as well as physically, connecting narrative for the Weststation area in transition. Basic acoustic principles form the foundation of the system-based design projects by Pelin Asa and Matheusz Modzelewski. Easy technical methods for filtering and amplifying sound waves have been used to facilitate a multiple use of public and private railway spaces. 


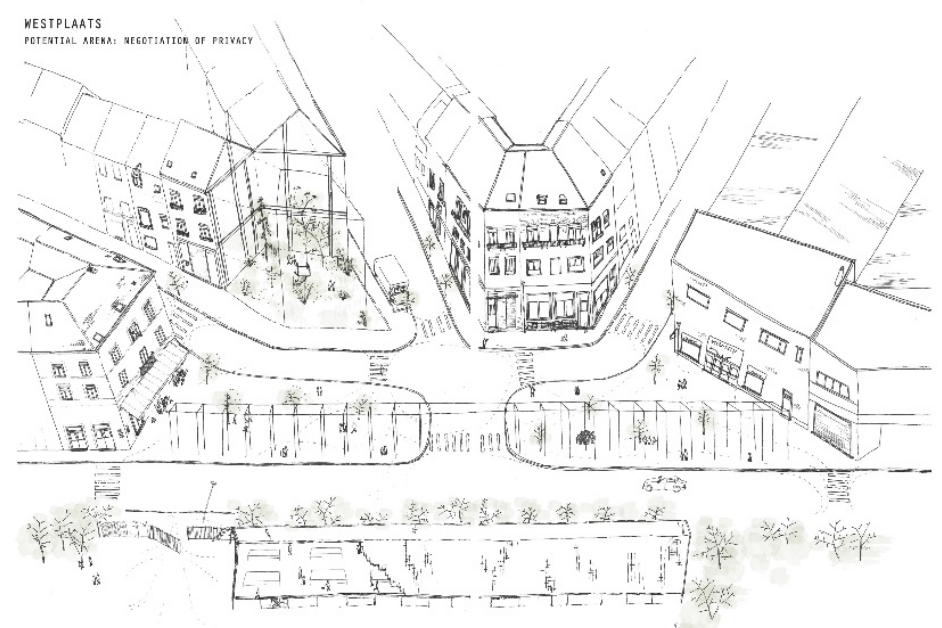

Fig. 6. Design for a potential arena for Westplaats by Leonie Van Bellingen

\subsection{Urban Sonic Design Typology}

On the basis of the design approach introduced and the final design proposals and propositions produced during the design studio, we identify four types of design approaches in relation to the disciplinary position and urban sonic forms applied in the projects:

- An interdisciplinary urban sound design approach in line with Augoyard and Torgue's suggestion of playing the city via its sonic Instrumentarium by modulating its vibrational effects. Within this we can distinguish a human versus non-human design approach.

- The noise landscape as opportunity for urban design. A transdisciplinary noise perspective allows for a gradually embracing of noise and an attitude of experiment. Noise oriented features are integrated in a green framework for urban design.

- $\quad$ The design of transitional architectural projects in which (sonic) vibrations are used as material for a re-negotiation. Ephemeral installations by means of artistic sonic strategies and techniques facilitate a disclosure of urban experience in a context of urban transformation. The experimental nature of the installation encourages an exploration of non-human agency in transitional planning.

- Concrete architectural approaches and projects that work with sound as material, and plan a design idea from an explicit acoustic perspective. The implementation of basic acoustic principles in relation to place-making allow for a controlled (re-) negotiation.

\section{Reflections and future directions}

In 2018, eleven students of the KU Leuven International Master in Architecture enrolled in a fourteen-week urban sound design research project under the guidance of Prof. Dr. Burak Pak and Drs. Caroline Claus. From an a-disciplinary questioning of human centered sonic conceptions and existing noise policies studies, students were challenged to move beyond the 
human centred sonic conceptions and to explore in practice, an a-disciplinary selection of sonic methods and forms, to exploit (sonic) vibrations as design material for a possible renegotiation of urban transition. From a mapping of the design practices, we have looked to the disciplinary positions the students departed from, and the urban sonic forms they designed for. From here we have set out the first lines of a typology that summarizes the practices and from where we proceed to the creation of concepts and/or a set of work arrangements that are at once material and processual.

Completing the evaluations of the Masterstudio_L28, at present, several challenges related to the a-disciplinary approach become clear. Due to the short duration of the project, the combination of different disciplines was difficult for teachers and students. Breaking the autopilot was not possible for all students. Increased complexity at all levels demands more participation, more knowledge and theoretical perspectives, introduction and experimentation with new tools and methods coming from multiple disciplines. The same applies to the reaching out to the super-diversity and complexity of Brussels. We observed how students can get lost in the ocean of practices. A form of guidance is necessary but more towards enabling the students to push through the frontiers they chose to challenge. Incompetence is bliss but also reduces the quality of the output in short time. At the level of the Faculty of Architecture and the research team, a shift from a-disciplinarity to transdisciplinarity demands more collaboration, connection with research groups active in other disciplines such as sound art and engineering. From a practical point of view, we also see the value in more cooperation for the supply of infrastructure, tools and space for this type of research and education.

\section{Acknowledgements}

KU Leuven Masterstudio_L28 is part of the ongoing PhD project: The Vibrational Nexus with Prof. Dr. Burak Pak as supervisor and Peter Cusack as co-supervisor. Participating students were Vilius Balčiūnas, Afanen Eman, Thorisaen Sarah, Ince Melisa, Modzelewski Mateusz, Vasudeo Doyel, Asa Pelin, Yin QI, Auris Alexander, Van Bellingen Leonie, and Daniel Dent Murgui.

Copyrights are protected and should not be shared by a third party.

\section{References}

1. Claus, C. (2018). Studio_L28: Sonic Perspectives on Urbanism. Brussels. Q-O2.

2. Kandjee, T., Pferdmenges, P. and Persijn, F. (2019) 'Project van Richtplan van Aanleg Weststation'. Perspective.

3. Mabilde, J. and Loeckx, A. (2016). Metropolitan landscapes. Brussel: Vlaams Bouwmeester.

4. "Het groene netwerk | Leefmilieu Brussel." 22 Sep. (2017), https://leefmilieu.brussels/groennetwerk. Accessed 24 Sep. 2018.

5. "Gare de l'Ouest | Perspective Brussels." http://perspective.brussels/en/node/602. Accessed 24 Sep. 2018.

6. Goodman, Steve. (2010). Sonic Warfare. Cambridge, Mass: MIT Press.

7. Augoyard, Jean François, and Henry Torgue. (2005). Sonic Experience. Montréal: McGillQueen's University Press. 
8. Schön, D. A. (1987). Educating the reflective practitioner. San Francisco: Jossey-Bass.

9. Newton C., Pak B. (2015) Virtuality and Fostering Critical Design Thinking: An Exploration of the Possibilities Through Critical Theory, Design Practices and Networked Learning. In: Jandrić P., Boras D. (eds) Critical Learning in Digital Networks. Research in Networked Learning. Springer, Cham.

10. Miessen, M. (2017). Crossbenching : towards a proactive mode of participation as a Critical Spatial Practice. Doctoral thesis, Goldsmiths, University of London

11. Schön, D. A. (1987).

12. Schön, D. A. (1983). The reflective practitioner: How professionals think in action. New York: Basic Books.

13. Miessen, M. (2017).

14. Schön, D. A. (1987).

15. Schön, D. A. (1983).

16. Schön, D. A. (1983).

17. Debord, G. (1958). Theory of the dérive. In K. Knabb (Ed. \& Trans.), (2006), Situationist International anthology (pp. 62-66). Berkeley, CA: Bureau of Public Secrets.

18. Westerkamp, H. (2007). Soundwalking. In A. Carlyle (ed.) Autumn Leaves: Sound and the Environment in Artistic Practice. Paris: Association Double-Entendre.

19. Augoyard, Jean François, and Henry Torgue. (2005).

20. Augoyard, Jean François, and Henry Torgue. (2005).

21. Blesser, B. (2007). Spaces Speak, Are You Listening? Experiencing Aural Architecture. The Journal of the Acoustical Society of America., 121(4), 1820-1821. 